\title{
Utility of antiapoptotic strategies in spinal cord injury: If you can dream it, you can do it!
}

\author{
Ali Khoynezhad, MD, PhD
}

From the Cedars-Sinai Heart Institute, Los Angeles, Calif.

Disclosures: Author has nothing to disclose with regard to commercial support.

Received for publication Aug 10, 2016; accepted for publication Aug 11, 2016; available ahead of print Sept 19, 2016.

Address for reprints: Ali Khoynezhad, MD, PhD, Cedars-Sinai Medical Center, 127 S. San Vicente Blvd, Suite A3306, Los Angeles, CA 90048 (E-mail: akhoy@cshs.org).

J Thorac Cardiovasc Surg 2016;152:1609-10

$0022-5223 / \$ 36.00$

Copyright (C) 2016 by The American Association for Thoracic Surgery

http://dx.doi.org/10.1016/j.jtcvs.2016.08.010

Spinal cord injury (SCI) after cardiovascular surgeries and traumatic injuries remains a dreaded complication with significant escalation of mortality and healthcare cost. ${ }^{1}$ The cause of early and delayed SCI after open and endovascular aortic operations is thought to be due to neuronal ischemic necrosis and ischemia-reperfusion-related apoptosis. ${ }^{2}$ When evaluating potential adjuncts to reduce or prevent SCI, antiapoptotic pharmaceutical and immunologic agents have the highest potential to become clinically important therapeutic options.

In this edition of the Journal, He and coworkers ${ }^{4}$ present promising results in the reduction of ischemia-reperfusioninduced SCI through antiapoptotic expression of microRNA-21 using intrathecal injection of lentivirus vectors in a rodent model. The authors' experiments build on established knowledge of microRNA-21, conducting a strong antiapoptotic effect on many cancer cells, cardiac myocytes, and neurons. MicroRNA-21 is a common brain effector and mediator in response to ischemic preconditioning. He and colleagues ${ }^{4}$ proclaim the reduction of SCI using clinical, histologic, and immunologic laboratory examinations. This represents exciting new knowledge, if reproduced and confirmed by upcoming animal experiments, with ramification and translational option into larger animal and human experiments.

However, there are a series of caveats with this reported series, listing 3 categories to follow. First, concerns relating to the used animal model: The caspase activation or apoptotic pathways in rats may be different than in humans. Furthermore, larger animals such as leporine ischemic SCI models generally are thought to be superior and more reliable than rodent models because of the similarity to human spinal cord vascular supply and dependable and reproducible spinal cord ischemia induction in rabbits. Second, uncertainties concerning the diagnostic tools used: The link between overexpression of microRNA-21 and regulation of tumor necrosis factor/

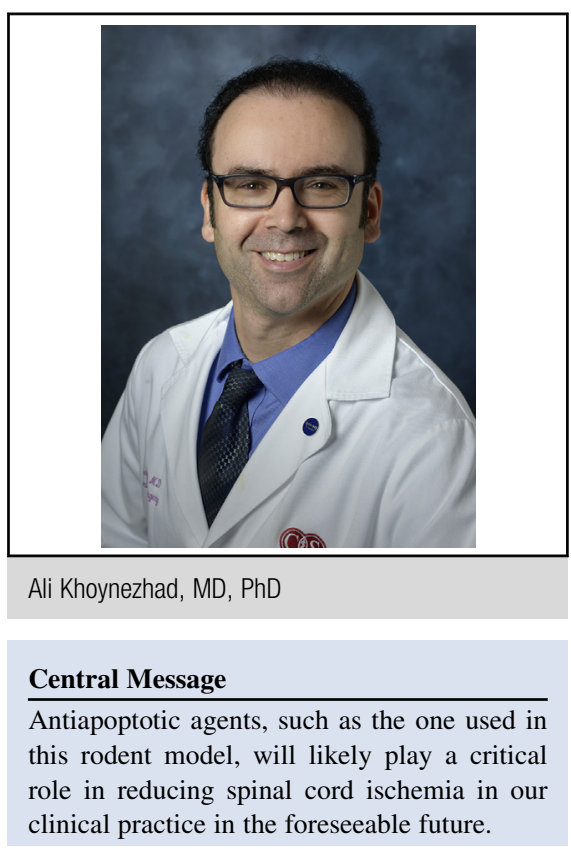

See Article page 1602 .

apoptosis proteins Fas ligand and programmed cell death 4 is not well established. The brevity and transience of neuronal apoptosis are culprits for the low sensitivity rates and inferiority of current diagnostic methods, including those used in current experiments. More accurate tools are needed for future studies and are being currently developed. Last but not least, limitation of knowledge in this expanding area of neuroimmunology: It is unclear whether antiapoptotic adjuncts for SCI could lead to alternative modes of neuronal death, such as necrosis, could increase autoimmune and lymphoproliferative disorders, or could have other significant clinical side effects in humans.

The prevention or attenuation of neuron apoptosis is an appealing therapeutic goal in the treatment of clinically horrific SCI data, and as we accumulate more data, the spectrum of potential therapeutic methods will likely widen. It is vital for physicians and scientists to further investigate these treatment options in animals and future human experiments. This reminds me of the quote attributed to Walt Disney underlying the importance of imagination and determination in our daily life: "If you can dream it, you can do it!",5 


\section{References}

1. Khoynezhad A, Donayre CE, Bui H, Kopchok G, Walot I, White RA. Risk sfactors of neurologic deficit after thoracic aortic endografting. Ann Thorac Surg. 2007;83: S882-9.

2. Griepp RB, Griepp EB. Spinal cord protection in surgical and endovascular repair of thoracoabdominal aortic disease. J Thorac Cardiovasc Surg. 2015;149(2 Suppl):S86-90.
3. Khoynezhad A, Jalali Z, Tortolani AJ. Apoptosis: pathophysiology and therapeutic implications for the cardiac surgeon. Ann Thorac Surg. 2004;78:1109-18.

4. He F, Ren Y, Shi E, Liu K, Yan L, Jiang X. Overexpression of microRNA-21 protects spinal cords against transient ischemia. J Thorac Cardiovasc. 2016;152:1602-8.

5. The truth about "if you can dream it, you can do It". Available at: http:// marciodisneyarchives.blogspot.com/2011/07/if-we-can-dream-it-we-can-do-it.html. Accessed September 2, 2016. 